\title{
AS (NÃO)REPRESENTAÇÕES DA PAISAGEM NO MOVIMENTO CUBISTA: PERCURSOS E INQUIETAÇÕES GEOGRÁFICAS NAS PINTURAS DE ALBERT GLEIZES
}

\author{
Jéssica Soares de Freitas \\ Doutoranda em Geografia pelo PPGeo UFG \\ jessicasoaresfreitas@gmail.com \\ Maria Geralda de Almeida \\ Professora titular do PPGeo-UFG \\ mgdealmeida10@gmail.com
}

\begin{abstract}
RESUMO
O movimento cubista, que rompe com as estruturas da pintura, rompe também com seus gêneros. No presente ensaio, será apresentado como o cubismo, pela ótica das obras de Abert Gleizes, pode contribuir para o estudo da representação e da paisagem na Geografia Cultural. Ao considerar que o movimento quebrou com mais impacto a representação e o gênero de pintura da paisagem, tem-se como objetivo compreender o conceito de paisagem e sua (não)representação com base no Cubismo. Para tal, realizou-se estudo principalmente em ensaios constituídos na época do movimento e em livros de história da arte em conjunto com textos geográficos. Como metodologia principal utilizaram-se as geografias criativas, com o intuito de aproximar a arte em diálogo com Geografia. Com tais motivações pode-se concluir que, se houve a ruptura, o gênero da paisagem ainda continua na pintura, bem como a representação. Outrossim, essa representação é olhada de maneira paralela para seus limites, ao se compreender a não representação, ao se entender a vivência da paisagem como prática.
\end{abstract}

Palavras-chave: Paisagem Cubista. Representação. Geografia Cultural. Geografias criativas.

\section{THE (NON)REPRESENTATIONS OF LANDSCAPE ON CUBIST MOVEMENT: GEOGRAPHICAL ROUTES AND CONCERNS IN ALBERT GLEIZES PAINTINGS}

\begin{abstract}
The Cubist movement, which breaks with the structures of the painting, also breaks with its genres. In this essay, it will be presented as Cubism, from the perspective of the works of Abert Gleizes, can contribute to the study of representation and landscape in Cultural Geography. When considering that the movement broke with more impact on the representation and the genre of landscape painting, it aims to understand the concept of landscape and its (non)representation based on Cubism. For this, a study was carried out mainly in essays constituted at the time of movement and in art history books together with geographical texts. As the main methodology, creative geographies were used, to bring art together in dialogue with Geography. With such motivations, it can be concluded that, if there was a rupture, the genre of the landscape is still in painting, as well as the representation. Moreover, this representation is looked parallel to its limits, when understanding non-representation, when understanding the experience of the landscape as a practice.
\end{abstract}

Keywords: Cubist Landscape. Representation. Cultural Geography. Criatives Geography.

Quando o mistério acaba, acaba o dever de imaginar... de entender...

mas o mistério da vida é aquele que nunca acaba - J. P. Novaes

\section{NO INÍCIO ÉRAMOS INDAGAÇÕES...}

O que é paisagem? Essa pergunta também se relaciona à questão enigmática "o que é arte"? Na arte, há debate acerca do que se caracterizaria como tal desde seus primórdios e o questionamento foi

$\begin{array}{lllll}\text { Caminhos de Geografia } \quad \text { Uberlândia-MG } & \text { v. 21, n. } 74 & \text { Abr/2020 } & \text { p. 87-107 } & \text { Página } 87\end{array}$


aprofundado ainda mais com as Vanguardas Europeias, quando se rompe radicalmente com o que até então era definido como arte (GOMBRICH, 2013). No concernente ao conceito paisagem, a discussão também é ampla, perpassando várias linhas teórico- metodológicas da Geografia. Neste ensaio, utilizaremos o conceito pela via das abordagens culturais em Geografia, que possui uma ampla discussão acerca desse conceito (ROSE, 2017).

As Vanguardas Europeias foram de fundamental importância para a constituição da arte contemporânea (ARGAN, 1992). A querela acerca do que é arte e os questionamentos de como a arte era constituída começaram a ser compostos pelos Impressionistas, mas foram os Cubistas que efetivaram a provocação de desafiar a Arte na condição de instituição (GOMPERTZ, 2012).

Apollinaire (2017 [1913], não paginado), um dos principais intelectuais do início do século XX e responsável pelo texto Les peintres cubistes: méditations esthétique, publicado originalmente em 1913, chama atenção que "Pablo Picasso dont les inventions corroborées par le bon sens de Georges Braque qui exposa, dès 1908, un tableau cubiste au Salon des Indépendants"1. Após a exposição, em 1910, outros artistas começaram a mostrar suas obras, aumentando o alcance do movimento.

Metzinger e Gleizes, dois dos principais artistas cubistas, foram responsáveis pelo primeiro ensaio Cubista no ano de 1912. Inspirados fundamentalmente na obra de Cézanne (METZINGER; GLEIZES, 1964 [1912]), os artistas afirmavam que era necessário estudar a profundidade cézanniana para se realizar e compreender obras cubistas.

Com tal inspiração, Argan (1992, p. 302) afirma que "a finalidade era transformar o Quadro numa formaobjeto que possuísse uma realidade própria e autônoma e uma função específica própria. Diante do quadro não é mais necessário perguntar o que ele representa, mas como funciona", afirma. A representação foi um questionamento importante durante o Cubismo, e por isso muitas vezes os espectadores ou críticos de arte subtraem a perspectiva da paisagem no Cubismo.

No entanto, Apollinaire (2017 [1913]) salienta que era recorrente o uso de títulos que vagamente diziam respeito ao gênero da obra como retrato, paisagem ou natureza morta. O gênero artístico da paisagem esteve presente, configurado muitas vezes como título, elemento abordado em algumas pinturas selecionadas no decorrer deste ensaio. Diante disso, compreender a paisagem por meio do movimento Cubista pode oferecer ao geógrafo outro olhar acerca do seu conceito.

Apoiando-se em Hawkins (2015, p. 251), para quem "from Modernist practices onward, challenges to representation have been standard artistic fare, with Cubism, for example, offering geographers rich empirical material to study artistic experimentation that challenge representations of time and space"2. $\mathrm{O}$ desafio de estudar o Cubismo, que propõe uma quebra com a representação na arte, é justamente a exposição/justaposição desafiadora do espaço-tempo que se desvela pela paisagem.

Para Serpa (2013, p. 170), "a paisagem resulta de um processo de acumulação, mas é, ao mesmo tempo, contínua no espaço e no tempo, é uma sem ser totalizante, é compósita, pois resulta sempre de uma mistura, um mosaico de tempos e objetos datados". No entanto, o resultado nem sempre é explicitamente datado e a composição da paisagem é realizada conforme o sujeito que a habita e reconhece.

Intenta-se, entremeio às pinturas do movimento cubista, problematizar os limites da representação e dos modos de compreensão da multiplicidade da paisagem nos pintores desse movimento. Para propiciar imersão no tema enfocar-se-á em um artista específico, Abert Gleizes. Esse cubista possui diversas pinturas de paisagem que desafiam a ordem e estrutura representativa até então associada a tal gênero. Por se tratar de uma arte vigorosa e profunda (APOLLINAIRE, 2017 [1913]), decorrente de amplo estudo, suas pinturas e seu ensaio em parceria com Metzinger (METZINGER; GLEIZES, 1964 [1912]) são as peças fundamentais na problematização realizada.

\footnotetext{
1 "Pablo Picasso, cujas invenções colaboraram para o bom senso de Georges Braque que expõe, em 1908, uma tela cubista no Salão dos Independentes" (APOLLINAIRE, 2017 [1913], n.p., tradução livre).

2 "Em diante das práticas modernistas, desafios para a representação tem sido padrão na prática artística, o Cubismo, por exemplo, oferece aos geógrafos rico material empírico para estudo de experimentação artística que desafiam as representações de tempo e espaço." (HAWKINS, 2015, p.251, tradução livre).
} 
O objetivo é compreender a paisagem como experiência empírica por meio do Cubismo, com o objetivo de decifrar as representações desafiadas pelos cubistas. Dessa maneira, a metodologia central do trabalho é efetivada por meio das Geografias Criativas, que propõem estudar a Geografia em corroboração com a arte, visando relacionar, de forma interdisciplinar, práticas criativas e a teoria (HAWKINS, 2015).

\section{O QUE REPRESENTA O CUBISMO?... O CUBISMO REPRESENTA?}

Associar o Cubismo com Representação gera diversas discussões. É comum nos livros de arte e nos de Geografia, quando debatida a arte, chegar-se à conclusão de que o movimento rompeu completamente com a representação (GOMBRICH, 2013). Mas houve de fato um rompimento completo? Ou por ele questionou-se a representação ao ponto de mostrar outra perspectiva, ou melhor, diversas perspectivas?

Segundo Argan (1992, p. 302), "na pintura de Cézanne, os objetos são decompostos e reconstruídos na trama do espaço; o quadro já não é a superfície sobre a qual se projeta a representação da realidade, e sim o plano plástico em que ela se organiza". Cézanne, grande inspirador do Cubismo, assim como Van Gogh e Gaugin, não pertencia a movimento artístico específico, mas inspirou vários. A obra cézanniana foi de grande importância para os Cubistas, pois, no lugar de representar o que se via, ele interpretava e utilizava a tela para promover o ponto de vista surgido daquela determinada relação com o ambiente a ser pintado.

Em seu estudo durante anos acerca do Mont Sainte-Victoire, Cézanne produziu diversas pinturas sobre a mesma montanha, cada uma com uma perspectiva diferente. $O$ objetivo também foi o de aprimorar a geometria da montanha por meio dos diversos ângulos que conseguia perceber (MERLEAU-PONTY, 2013). Esse modo de olhar, de perceber os objetos, as paisagens, foi sua herança tomada pelos cubistas. Os artistas desse movimento aprofundaram seu foco na geometria e nas perspectivas do observado.

Refere Cosgrove (1998 [1984], p. 54):

Geometrical continuity and new transformational rules between geometrical forms are propounded in a treatise by Poncelet written at the same time that Constable and Turner were exploring light and atmosphere in landscape in ways that implicitly challenged the dominance of linear perspective for space composition. Finally von Staud in the 1840s eliminated metrical ideas from perspective geometry, revealing the possibility of a nonEuclidian space and n-dimensional constructions. His work was completed by $\mathrm{F}$. Klein in 1875 a little before modernists eliminated perspective from space composition and at the same time as the first patents were taken out for modern photographic printing techniques. $^{3}$

A transformação das regras da geometria e utilização de uma perspectiva não euclidiana começaram anos antes dos modernistas. Aos poucos a linearidade nas pinturas foi reduzida a ponto de elas se transformarem completamente para além do espaço euclidiano.

O desafio da representação da paisagem pela perspectiva de um espaço não euclidiano e que transcenda três dimensões é uma razão que intriga os estudos sobre esse movimento. Como a representação era compreendida como algo dotado de certa imobilidade dentro da técnica de pintura tradicional, a partir do momento em que se colocam diferentes perspectivas de um mesmo objeto, ou no caso, de uma paisagem, a representação é imediatamente questionada.

A preocupação de Cosgrove (1998 [1984], p. 21) com a paisagem se pauta principalmente em sua representação, conforme afirma: "[...] with the rise of modernist and other forms of nonrepresentational art in the past 100 years landscape has lost much of its claim to be an important preoccupation of progressive

\footnotetext{
3 "Continuidade geométrica e novas regras transformacionais entre formas geométricas são postuladas em um tratado de Poncelet escrito ao mesmo tempo em que Constable e Turner estavam explorando luz e atmosfera na paisagem de modos que implicitamente desafiaram o domínio da perspectiva linear para composição espacial. Finalmente, von Staud, na década de 1840, eliminou as ideias métricas da perspectiva geométrica, revelando a possibilidade de um espaço não-Euclidiano e construções $n$-dimensionais. Seu trabalho foi completado por $F$. Klein em 1875, pouco antes dos modernistas eliminarem a perspectiva na composição espacial e, ao mesmo tempo que as primeiras patentes para impressão fotográfica moderna foram registradas." (Cosgrove, 1998 [1984], p; 54, tradução livre) 
artists"4. No entanto, na concepção de Argan (1992) a pintura de paisagem foi um importante gênero dos movimentos modernistas, principalmente se se considerar o começo do movimento no Romantismo ${ }^{5}$.

De acordo com Metzinger e Gleizes (1964 [1912], p. 8), "if we wished to tie the painter's space to a particular geometry, we should have to refer it to the non-Euclidean scientists; we should have to study, at some length, certain of Riemann's theorems". 6 Mesmo que a necessidade de se amarrar a uma geometria não seja o centro, as teorias mais utilizadas pelos cubistas são as não euclidianas, como já apontado por Cosgrove (1998 [1984]).

Figura 01 - Albert Gleizes. Paisagem (1912). Óleo s/ tela, 50,3 x 65,4 cm. Acervo Museu Solomon R. Guggenheim, Nova York.

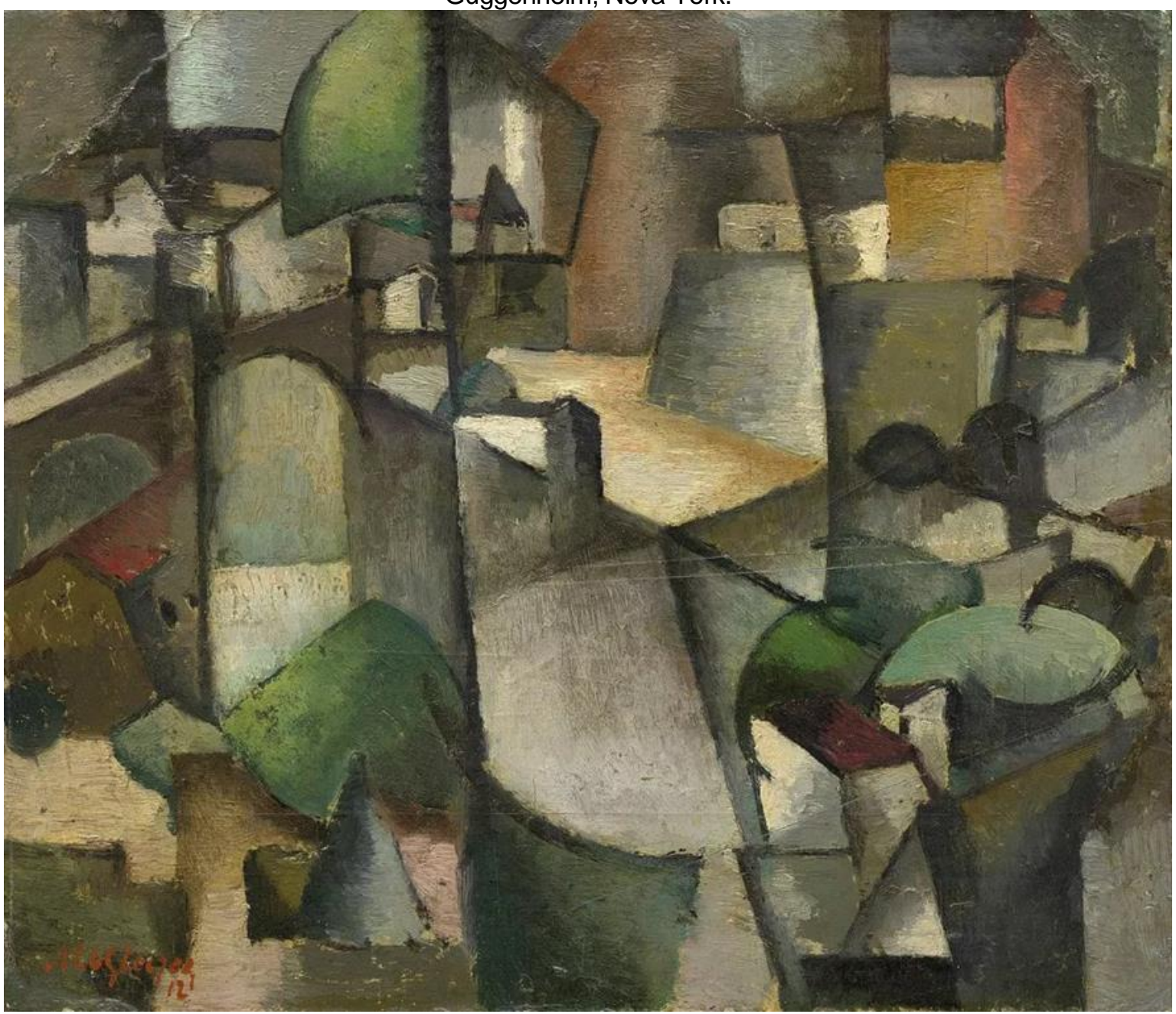

A pintura Paisagem (Figura 01), de Albert Gleizes, evidencia essa ruptura geométrica, mas ao mesmo passo é possível (re)construir a paisagem nela. A composição de cores, nem sempre da mesma tonalidade para um mesmo elemento, com pinceladas fortes e com profundidade, favorece uma perspectiva de transcendência da tridimensionalidade da obra.

4 "Com o crescimento do modernismo e outras formas de arte não representacional nos últimos 100 anos, a paisagem tem perdido muito de reivindicação para ser uma importante preocupação dos artistas progressivos." (COSGROVE, 1998 [1984], p.21, tradução livre).

${ }^{5}$ Cosgrove (1998 [1984]) deixa implícito que considera o começo do Modernismo no Impressionismo, no entanto para o ensaio consideramos a perspectiva de Argan (1992) e Gombrich (2013), cujos consideram que o Modernismo é iniciado no Romantismo.

6 "Se nós queremos prender o espaço do pintor a uma geometria particular, nós devemos nos referir aos cientistas não-euclidianos; nós devemos estudar, em algum momento alguns teoremas de Riemann. Metzinger e Gleizes" (1964 [1912], p. 8, tradução livre).

$\begin{array}{lllll}\text { Caminhos de Geografia } \quad \text { Uberlândia-MG } & \text { v. 21, n. } 74 \quad \text { Abr/2020 } & \text { p. 87-107 } & \text { Página } 90\end{array}$


Podemos ver, assim, uma paisagem formada de várias perspectivas, cuja ordem de geometria possui linhas retas e ângulos fechados. As árvores com diferentes formatos, as casas de diferentes tamanhos e formas, uma ponte que ao fundo encaminha o olhar do observador para o rio, tudo isso voltado para a intenção do artista, que no caso não é de representar algo, mas de instigar o espectador.

A forma como a luz é apresentada na obra é bem diferente de obras românticas de paisagens como de John Constable e Willian Turner, que também experimentaram diferentes formas de luz em suas obras. Segundo Metzinger e Gleizes (1964 [1912], p. 11), "it was then that the Cubists taught a new way of imagining light. According to them, to illuminate is to reveal; to color is to specify the mode of revelation. They call luminous that which strikes the mind, and dark that which the mind has to penetrate". ${ }^{7}$ No cubismo, a maneira com que se utiliza a luz para intensificar a experiência da mente revela o desejo de aproximação com as experiências, mais que o sentido da representação pela representação. Além disso,

\begin{abstract}
We do not automatically associate the sensation of with white the idea of light, any more than black with the idea of darkness. We admit that a black jewel, even if of a matte black, may be more luminous than the white or pink satin of its case. Loving light, we refuse to measure it, and we avoid the geometric ideas of focus and ray, which imply the repetition - contrary to the principle of variety which guides us - of light planes and dark intervals in a given direction. Loving color, we refuse to limit it, and sober or dazzling, fresh or muddy, we accept all the possibilities contained between the two extreme points of the spectrum, between the cold and the warm tone. (METZINGER; GLEIZES, 1964 [1912], p. 11). ${ }^{8}$
\end{abstract}

Tais características, presentes em Paisagem (Figura 01), aumentam as possibilidades de uso de cores e de maneiras de iluminação, além das formas sem um padrão específico. Obviamente, todos os artistas que participaram do movimento têm suas particularidades. No ensaio de Metzinger e Gleizes, os autores/artistas propõem mostrar os aspectos mais gerais utilizados pelos cubistas.

$\mathrm{Na}$ obra de Gleizes (Figura 01), a paisagem possui cores escuras e claras para um mesmo objeto, se assim podemos denominar, como a árvore. Cada ângulo tem uma tonalidade e aproximação de luz diferente. Se observada a ponte no lado esquerdo da tela, dada a profundidade, que pode ser caracterizada como o rio, é possível evidenciar-se que as cores se transformam conforme a intensidade da pincelada e da possível percepção do artista.

Assim, percebe-se um aspecto que deriva da utilização de teorias não euclidianas e que permite o universo de dimensões e visões baseadas na perspectiva do artista e do espectador, que vão ser diferentes. Apollinaire (2017 [1913]), Cosgrove (1998 [1984]) e Metzinger \& Gleizes (1964 [1912]) apontam a preocupação dos pintores cubistas com as diferentes perspectivas geométricas.

Segundo Apollinaire (2017, não paginado), "on a vivement reproché aux artistes-peintres nouveaux des préoccupations géométriques. Cependant les figures géométriques sont l'essentiel du dessin. La géométrie, science qui a pour objet l'étendue, sa mesure et ses rapports, a été de tous temps la règle même de la peinture" 9 . Esse entendimento da geometria, especificamente da perspectiva não euclidiana, abre um paralelo que vai além das três dimensões da geometria convencional. A teoria euclidiana é centrada nas linhas e ângulos como entidades baseadas em postulados fixos e calculáveis com precisão, mostrando poucas alterações decorrentes do devir. Nesse sentido, continua o autor:

\footnotetext{
7 "Foi assim que os Cubistas pensaram uma nova maneira de imanizar a luz. De acordo com eles, iluminar é revelar; a cor é para especificar a forma de revelação. Eles chamam luminosos cada golpes de mente, e escuros para cada mente tem que penetrar." Metzinger e Gleizes (1964 [1912], p. 11, tradução livre).

8 "Nós não associamos automaticamente a sensação do branco com a ideia de luz mais do que o preto com a ideia de escuridão. Nós admitimos que uma joia preta, mesmo que de um preto mate, pode ser mais luminosa que o cetim branco ou rosa de sua caixa. Por amarmos a luz, nos recusamos a medi-la, e nós desviamos das ideias geométricas de foco e raio, que implicam na repetição - contrário ao princípio de variedade que nos guia de planos luminosos e escuros em intervalos de uma dada direção. Por amarmos as cores, nos recusamos a limita-la, seja sóbria ou exagerada, fresca ou pantanosa, nós aceitamos todas as possibilidades contidas entre dois pontos extremos do espectro, entre o tom frio e quente." (METZINGER; GLEIZES, 1964 [1912], p.11, tradução livre).

9 "houve uma crítica severa aos artistas-pintores pelas suas novas preocupações geométricas. Contudo, as figuras geométricas são o essencial do desenho. A geometria, ciência que tem por objeto extensão, medidas e relações, foi sempre uma regra da pintura." (APOLLINAIRE, 2017 [1913], n.p., tradução livre).
}

\begin{tabular}{|c|c|}
\hline Caminhos de Geografia & Uberlândia-MG \\
\hline
\end{tabular}


Les nouveaux peintres, pas plus que leurs anciens ne se sont proposés d'être des géomètres. Mais on peut dire que la géométrie est aux arts plastiques ce que la grammaire est à l'art de l'écrivain. Or, aujourd'hui, les savants ne s'en tiennent plus aux trois dimensions de la géométrie euclidienne. Les peintres ont été amenés tout naturellement et, pour ainsi dire, par intuition, à se préoccuper de nouvelles mesures possibles de l'étendue que dans le langage des ateliers modernes on désignait toutes ensemble et brièvement par le terme de quatrième dimension. (APOLLINAIRE, 2017 [1913], não paginado). ${ }^{10}$

A pintura cubista, ao estudar e aplicar a Geometria não euclidiana, em ascensão no começo do século XX, propõe uma quarta dimensão. Essa transcenderia os nexos das linhas retas, ao utilizar uma junção da geometria elíptica com a hiperbólica. Com o emprego de tais formas, as duas dimensões, que já haviam aos poucos sido abandonadas pelos artistas, também desafiam a terceira dimensão, propondo um espaço geométrico dentro da pintura sem limites estruturais.

É nesse denso e inovador contexto que Metzinger e Gleizes (1964 [1912]) afirmam que "Cubism, which has been accused of being a system, condemns all systems". ${ }^{11}$ Por utilizarem fórmulas, cálculos e formas geométricas, aparentes em suas pinturas, os cubistas muitas vezes são ligados a uma estrutura fechada e muito calculada, em que há pouca margem para a liberdade do pintor. Exceto para alguns artistas obcecados pelas formas aplicadas de maneira "correta" (APOLLINAIRE, 2017 [1913]), o Cubismo propõe uma releitura da geometria estabelecida na forma de utilização de cores e perspectivas. O estudo de uma quarta dimensão libera os artistas das amarras da academia de artes e das fórmulas baseadas nos renascentistas (ARGAN, 1998).

Compreender essa quarta dimensão possibilita decifrar, mais que o papel da representação nas obras cubistas, a problematização da própria natureza do conceito de paisagem. Afirma Apollinaire (2917 [1913], não paginado):

Telle qu'elle s'offre à l'esprit, du point de vue plastique, la quatrième dimension serait engendrée par les trois mesures connues: elle figure l'immensité de l'espace s'éternisant dans toutes les directions à un moment déterminé. Elle est l'espace même, la dimension de l'infini; c'est elle qui doue de plasticité les objets. Elle leur donne les proportions qu'ils méritent dans l'œuvre, tandis que dans l'art grec par exemple, un rythme en quelque sorte mécanique détruit sans cesse les proportions. ${ }^{12}$

A quarta dimensão proporciona que a pintura demonstre a plasticidade dos objetos, que abarque o espaço como dimensão do infinito, ou seja: o tempo. As três dimensões euclidianas, comprimento, largura e profundidade, são questionadas por meio da geometria não euclidiana. A questão não é negá-las, mas acrescentar novos elementos, dentre eles o que os artistas cubistas denominam de quarta dimensão, como o tempo.

Nessa época, sobretudo após o livro A máquina do tempo (1895) de H. G. Wells, a elasticidade do tempo era cada vez mais uma inquietação de inúmeras possibilidades científicas e filosóficas. É nítido que antes do século XX já havia discussões sobre a dimensão do tempo e do espaço. Mas o tempo, que até então nas pinturas era transmitido de maneira "congelada" para se entender e preservar aquele momento específico que era pintando, foi considerado nas pinturas cubistas como uma quarta dimensão

10 "Os novos pintores, não mais que os antigos, se propõem a serem geómetras. Mas, nós podemos dizer que a geometria está nas artes plásticas do mesmo modo que a gramática é a arte do escritor literário. Ou, atualmente, os estudiosos não se limitam mais às três dimensões da geometria euclidiana. Os pintores foram trazidos naturalmente e, por assim dizer, pela sua intuição, à preocupação sobre as novas medidas possíveis para o entendimento da linguagem dos ateliês modernos, no que pode agrupar-se e designar sucintamente pelo termo quarta dimensão." (APOLLINAIRE, 2017 [1913], n.p., tradução livre).

11 "Cubismo, que tem sido acusado por ser um sistema, condena todos os sistemas." (Metzinger e Gleizes (1964 [1912], tradução livre).

12 "Como aquela que se oferece ao espírito, do ponto de vista plástico, a quarta dimensão está engendrada por três medidas conhecidas: ela dimensiona a imensidão do espaço que se eterniza por todas as dimensões de um determinado momento. Ela é o espaço mesmo, a dimensão do infinito: é ela que garante a plasticidade dos objetos. Ela os transmite as proporções que merecem em uma obra, como na arte grega, onde, por exemplo, há um ritmo de certa forma mecânico em que as proporções são destruídas sem cessar." (APOLLINAIRE, 2017 [1913], n.p., tradução livre)

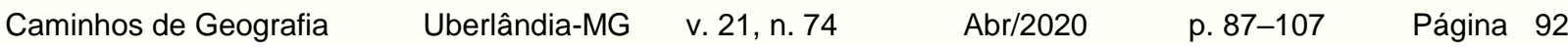


(AMBROSIO, 2016). Essa mudança centraliza a ideia de que aquele momento transmitido na pintura não é único e nem demonstra um lugar específico por si mesmo.

Uma das primeiras pinturas que levaram ao aprofundamento de uma quarta dimensão foi Les Demoiselles d'Avignon, de 1907, assinada por Pablo Picasso (GOMBRICH, 2013). Tanto Picasso quanto Braque foram os pioneiros em utilizarem objetos fixos, como violinos, natureza morta, ou mesmo a paisagem (APOLLINAIRE, 2017 [1913]).

Mas por que a pintura deixa de representar o mundo por meio de formas bidimensionais ou mesmo tridimensionais, já que, na tela, tais características eram mais aceitas e entendidas pelo público? Argan (1992) argumenta que com as mudanças tecnológicas e científicas a fotografia ocupou tal função, assim como o cinema teoricamente ocupou a função do teatro. Cabiam, então, a metamorfose de abordagem e a liberdade criativa de questionamentos que as vanguardas realizaram como modo de mobilizar a arte do período.

Em Paisagem (Figura 01) não importa o lugar em que foi realizada a pintura em si, pois a representação da paisagem manifesta-se como resultado da composição de diversos elementos dela. Arquiteta-se uma paisagem que é conhecida naquele momento por aquele que vê a pintura. Os elementos conhecidos, as árvores, pontes e casas, são, dessa forma, colocados em diversas perspectivas e locais, buscando revelar a plasticidade e infinitude do tempo.

On Brooklyn Bridge (1917) (Figura 02) é uma pintura de uma série realizada acerca da ponte do Brooklyn em Nova York. A estrutura em ferro, marco da modernidade arquitetônica que encantava vários artistas, foi fonte de inspiração e arte durante os anos de 1915 e 1917. É evidente uma visão de modernidade centrada em Nova York, que após a I Guerra Mundial virou um dos maiores centros artísticos (GOMPERTZ, 2012), em virtude, sobretudo, da presença de artistas como Gleizes.

Para Hughes (1991), a celebração da modernidade dessa pintura também nos encaminha ao futurismo, mesmo que o artista em si não tenha participado do movimento. Concomitante ao movimento Cubista, o Futurismo se iniciou com o Manifesto Futurista de Marinetti, publicado em 1909 (ARGAN, 1992), e aos poucos foi aderido por outros artistas como Boccionne e Duchamp.

O último, integrante do movimento Cubista, tem uma das principais obras do movimento futurista, $\mathrm{Nu}$ descendo a escada, de 1912. Ela é uma mistura do Cubismo com o Futurismo. No entanto, neste, o principal elemento era o movimento, inspirado justamente nas mudanças da modernidade, de forma a celebrá-la.

Historicamente, mesmo que o Futurismo tenha sido importante para o desenvolvimento da arte, sua obsessão nas máquinas e na utopia, o que pouco tempo depois com a $1^{\text {a }}$ Guerra Mundial foi questionado, acarretou a redução do movimento, principalmente pelo fato de seus principais membros fundadores, Boccionne e Marinette, aderirem ao movimento Fascista (GOMPERTZ, 2012).

Gleizes contrapõe o futurismo em suas pinturas, ao passo em que não se trata exatamente da apologia da modernidade sobre o sujeito. Seu encantamento com a utopia modernista de Nova York vem de outra fonte: das formas e entrelaces que a ponte transmite. Os traços, nessa pintura (Figura 02), são bem diferentes de Paisagem (Figura 01), bem como a utilização de cores e das pinceladas mais leves, revelada em outras obras tardias.

Pode-se perceber que o momento da pintura não é relevante, posto que o tempo revelado pode ser compreendido como se a obra fosse feita na contemporaneidade, sem ser uma representação específica unicamente daquela ponte. As formas, profundidade e não linearidade aparecem com mais destaque que na pintura anterior (Figura 01).

Por isso o movimento Cubista, assim como o Futurista e o Surrealista, aprofunda o que se chama de pintura não representacional. Ainda que, segundo Metzinger e Gleizes (1964 [1912], p. 13), "the only difference between the Impressionists and ourselves is a difference of intensity, and we do not wish it to be otherwise"13, eles foram muito além. No impressionismo ainda podíamos ver pinturas representacionais de maneira mais nítida que no cubismo.

13 "a única diferença entre os Impressionistas e nós mesmos é a diferença de intensidade, e nós não desejamos que fosse de outra forma." (METZINGER E GLEIZES, 1964 [1912], p. 13, tradução livre). 
Figura 02 - Albert Gleizes. On Brooklyn Bridge (1917). Óleo s/ tela, 161,8 x 129,5 cm. Acervo Museu Solomon R. Guggenheim, Nova York.

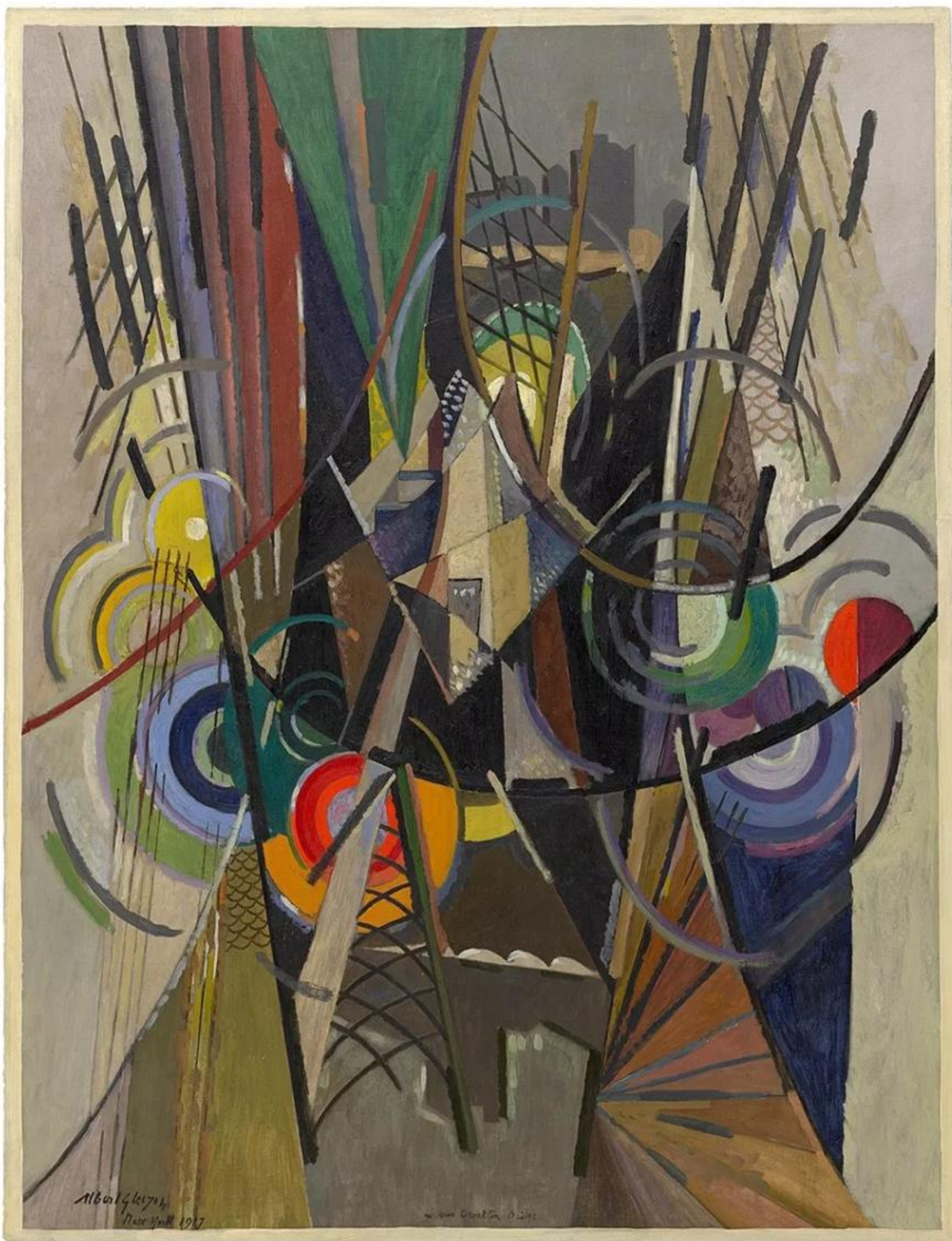


Entre todas as características do movimento, já estabelecidas pelos historiadores da arte, a sua forma não representacional (AMBROSIO, 2016) é um elemento que nos interessa como geógrafos (HAWKINS, 2015). É imperioso, logo, compreender o porquê e se realmente a arte cubista é não representacional e como tal questão pode expandir a perspectiva geográfica da paisagem. Ferraz (2009, p. 30) assinala:

\begin{abstract}
Olhar certa paisagem e representá-la pictoricamente é uma tradição que acompanha o homem desde os primeiros passos de sua evolução racional, emocional e civilizatória, ou seja, um ser que pensa/sente o mundo, tenta comunicar suas impressões para um ser outro por meio de palavras (escritas ou orais) e imagens (desenhadas, gestuais, pintadas e expressões diversas), de forma a gerar sentido de compreensão, identificação, incômodo e interpretação-recriação das representações por ele elaboradas.
\end{abstract}

A representação, como já discorrido, era algo, e ainda é, particularmente relevante na pintura, se considerarmos movimentos como o Hiper-Realismo na contemporaneidade. Seus pensamentos, sentimentos, como no Romantismo, por exemplo, em pinturas como de Turner, são representados na tela e, dessa forma, são expostos seus pensamentos ao observador.

Até então se pode compreender que o cubismo também faz tal relação, mas de uma maneira diferente. Não se representam as formas exatas, propiciando que imediatamente se identifique o objeto demonstrado na pintura. Em On Brooklyn Bridge (Figura 02), a reação perceptiva inicial não é a conexão psicológica com a ponte do Brooklin, mas a de qualquer outra obra arquitetônica parecida ou análoga. Apenas após observar o título da obra há entendimento daquilo que o autor diz que foi representado originalmente. Contudo, ainda é possível imaginar qualquer tempo e espaço por meio da obra.

Para Almeida (2003, p. 72), "as representações são fundadas sobre a aparência dos objetos e não sobre os objetos em si". Ao considerar a representação como uma apresentação do objeto, uma perspectiva dele, pode-se entender que há um resíduo de representação na arte cubista. O cubismo não nega completamente a representação, ele a desafia. Sobre a representação, Gil Filho (2005, p. 53-54) argumenta:

[...] a representação é expressão concreta, quer por manifestação, quer por emanação de uma vontade incontida do aqui e agora, e não admite redução a nenhuma outra forma semelhante. A individuação da representação é expressa por meio de formas concretas mediadas pela linguagem. Como fenômenos sensíveis, as formas se revestem de sentido através de seu âmbito.

A pintura, uma forma de linguagem, revela um mundo de significados. Entretanto, sobre o que o Cubismo nos fala? As formas que Paisagem (Figura 01) e On The Brooklin Bridge (Figura 02), comunicadas por Gleizes, nos revelam mais do que um mundo de significados, mas mundos de significados.

Gil Filho (2005, p. 56) complementa que "as representações remetem à consciência coletiva, que explica o que é de interesse imediato e acessível a qualquer um. Seria a realidade prática, apreendida através da apropriação comum da linguagem e da imagem, e de sua veiculação de idéias". Nesse sentido, as representações estão ligadas à coletividade, ao passo que é o coletivo que forma as imagens a serem postas por meio da representação.

Contudo, o modo efetivo dessa comunicação exige o conhecimento de alguns elementos, ainda que não necessariamente de forma concreta. Pela via da fenomenologia de Bachelard (2008, p.159), "a Representação é dominada pela Imaginação. A Representação não é mais que um corpo de expressões para comunicar aos outros nossas próprias imagens". É por meio da imaginação que a representação comunica o que cada sujeito tem em suas percepções.

Assim, a representação toma um caráter que pode ser mais subjetivo e individual. É por meio da perspectiva do sujeito que a representação é formada. No entanto, o sujeito não está fora do coletivo. Ele está inserido em uma forma de relação simbiótica entre o eu e o mundo. As pinturas selecionadas, portanto, revelam um mundo imaginário do pintor mediante sua percepção dos objetos, sua imaginação do que é apresentado na tela.

É possível considerar que "as representações enchem o espírito dos homens, mas elas circulam entre eles. Elas não aparecem fundamentalmente como realidades individuais. Elas são de natureza social" (CLAVAL, 2008, p. 18). As representações são formadas graças à coletividade, conforme apontado também por Gil Filho (2005) e Almeida (2003).

No sentido artístico de representação, de acordo com Berque (1989, p. 19), "en Europe, la représentation du paysage a traversé depuis le XIXe siècle (entre l'Ecole de Fontainebleau, Cézanne et les modernes) la

$\begin{array}{lllll}\text { Caminhos de Geografia } \quad \text { Uberlândia-MG } & \text { v. 21, n. } 74 \quad \text { Abr/2020 } & \text { p. 87-107 } & \text { Página } 95\end{array}$


crise que l'on connaît. Quand on pense que la notion de paysage est née de la peinture, cela pose problème". ${ }^{14}$ Segundo o autor, a crise da representação, principalmente no gênero paisagem, foi manifestada pelos modernistas. Esses movimentos contribuíram para que a paisagem não fosse mais representada de uma maneira tradicional, e, na interpretação do autor, não mais formulada pela pintura.

Em contraponto, os próprios cubistas apontam que "[...] we do not intend to provide definitions; we only wish to suggest that the joy of taking by surprise an art undefined within the limits of the painting, is worth the effort it demands, and to incite to this effort whoever is worthy of the task"15 (METZINGER; GLEIZES, 1964, p. 2). A representação pode ser considerada um dos limites da pintura até o momento em que os modernistas provocam uma ruptura. Entretanto, não há exatamente um rompimento completo.

Há uma linha tênue na "quebra" da representação no Cubismo, visto que geralmente deixamos de utilizar pinturas desse movimento para explicações da realidade. Essa postura é diferente da que é interpretada em relação ao Romantismo ou o Impressionismo. Como o movimento cubista não representa a realidade em si, mas o que se vê e se percebe para além das formas que não são lineares, as explicações com base em uma visão euclidiana de espaço nas fronteiras dos estudos do conceito de paisagem ficam comprometidas.

Para Söderström (2005, p. 11), "representation is at the core of scientific practice. It is even often seen as summarizing the whole process of knowledge production. The critique of this equation (science/knowledge = representation) has been a central issue in modern philosophy". ${ }^{16}$ A crítica do autor se baseia na maneira como tratamos a representação: ora como coletivo, ora individual, ora baseada no conhecimento não apenas o científico.

Pela via da não representação, aqueles que aderem a tal teoria não negam ou eliminam totalmente a representação, mas questionam suas limitações, principalmente em estudos contemporâneos e naqueles em que não há um todo, mas partes, como a arte Cubista. Nesse sentido, a não representação corrobora para compreender aquilo que a representação possa vir a ser limitadora (DEWSBURY, 2014).

Söderström (2005, p. 14-15) complementa acerca da representação:

No longer more or less correct mental images, they are seen as one of the elements in a network of human and non-human distributed intelligence, which constantly transforms the world we inhabit. This means that geographers are (and, probably increasingly, will be) analysing the interplay between different forms of representations of space - in maps, photographs, cinema, etc. - and fields of practice, such as patterns of behaviour in the urban environment or urban planning. They study, in other words, 'representations in the wild' (i.e. having escaped from the prison house of the cogito). ${ }^{17}$

O que se questiona, logo, é a representação "clássica"; e até que ponto, também, ainda podemos utilizá-la sem certa criticidade contextual. No Cubismo, como visto em Paisagem (Figura 01) e On the Brooklin Bridge (Figura 02), a ruptura com a representação está longe de ser completa. Além do mais, ela possui limites para compreendermos as paisagens cubistas.

Por ser tão complexo, o cubismo pode levar os geógrafos a pensarem em diversos estudos pela ótica do conceito da paisagem, mas também pelo lugar. Guernica, de Pablo Picasso, e as próprias pinturas do Gleizes, Brooklin Bridge (1915) e On the Brooklin Bridge (1917), podem ser estudos férteis para tanto.

14 "Na Europa, a representação da paisagem depois do século XIX (entre a escola de Fontainebleu, Cézanne e os modernos) atravessa a crise que conhecemos. Quando se pensa que a noção de paisagem é nascida na pintura, isso se apresenta como um problema." (BERQUE, 1989, p.19, tradução livre).

15 "nós não temos a intenção de prover definições; nós apenas queremos sugerir que a alegria de ser surpreendido em uma arte não definida sem os limites da pintura, vale o esforço que é exigido, e iniciar qualquer esforço é válido." (METZINGER; GLEIZES, 1964, p. 2).

16 "Representação é o core da prática científica. Tem até sido visto muitas vezes como resumo de todo processo da produção de conhecimento. A crítica dessa equação (ciência/conhecimento = representação) tem sido um problema central na filosofia moderna." (SÖDERSTRÖM, 2005, p.11, tradução livre).

17 "Não mais ou menos imagens mentais corretas, eles são vistos como um dos elementos em uma rede de inteligências humanas e não-humanas, que constantemente transforma o mundo que habitamos. Isso significa que os geógrafos estão (e, provavelmente, estarão cada vez mais) analisando a interrelação entre diferentes formas de representações do espaço - em mapas, fotografias, cinema, etc. - e campos de prática, como padrões de comportamento no ambiente urbano ou planejamento urbano. Eles estudam, em outras palavras, 'representações no mundo selvagem' (isso é, havendo escapado da prisão do cogito)." (SÖDERSTRÖM, 2005, p. 14-15, tradução livre).

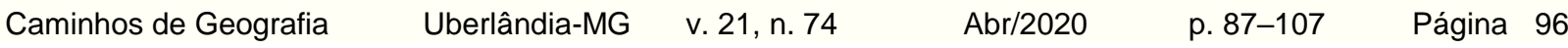


Ademais, o debate da representação no Cubismo tem muito a ser aprofundado. Neste ensaio, utilizaremos a paisagem para buscarmos aprofundar o que foi apresentado até o momento.

\section{PAISAGEM, PAISAGENS...}

Ao pensar em paisagem na arte, no geral, nos remetemos aos clássicos, ou aos românticos, no máximo aos impressionistas. A dúvida se o Cubismo, além de "quebrar" a representação como até então sistematizada, também rompeu a paisagem, gera-nos múltiplos desafios e uma inquietação que incita curiosidades geográficas.

O conceito de paisagem perpassa múltiplas temáticas e subdisciplinas na Geografia, como Geomorfologia, Climatologia, Geografia Urbana e, foco deste trabalho, a Geografia Cultural. Na Geografia Cultural há um longo histórico do estudo da paisagem em suas diversas abordagens (ROSE, 2017).

Ao se procurar entender seus limites e as abordagens utilizadas, a paisagem será estudada, neste ensaio, principalmente pela perspectiva pós-moderna em sua potencialidade de transdisplinaridade. Para Almeida (2013, p. 246), o "pós-modernismo prosperou com a crença de que paisagens estão repletas de contradições e definir o espaço é um exercício de grande complexidade". Ao observar essa perspectiva em junção aos nexos do movimento cubista, tal abordagem adentra no fato de que a paisagem é complexa.

Apollinaire (2017, não paginado) pondera que "il faut aux nouveaux artistes une beauté idéale qui ne soit plus seulement l'expression orgueilleuse de l'espèce, mais l'expression de l'univers, dans la mesure où il s'est humanisé dans la lumière". ${ }^{18} \mathrm{O}$ belo expressado pelos românticos (GOMBRICH, 2013), para os cubistas, é um belo não advindo da própria natureza, mas do universo, da humanidade em si, uma transcendência tempo-espacial de sobreposições ponderadas pelas pinceladas. Há uma complexidade expressiva daquilo que se abre pela paisagem posta nas telas.

Dessa forma, o cubismo revela as mudanças entre a ideia de espaço e tempo como elementos essenciais para a pintura e para a paisagem de maneira datada e representacional. Abordar tal gênero, dentre outros fatores, corrobora para tal discussão e escolha de abordagem. Refere Berger (2003, não paginado):

What is this painting of a landscape? It is said that landscape painting has died a natural death. Certainly there are no great modern landscapes comparable to those of the past. But what of those which are not comparable? Which are not even landscapes? For that is the point: the genre has changed beyond recognition. Cubism when it broke painting broke the landscape too. It is unlikely that the specific appearance of a given landscape will ever again be the aim of an important painter. But it can well be his starting point. Landscape painting must now be subsumed under Painting. That is all that natural death means. ${ }^{19}$

Mesmo que o gênero de paisagem na pintura tenha a aparência de ter desaparecido, há pintores famosos na atualidade que pintam paisagens sem ser apenas uma "prática" ou ponto inicial para aprendizagem. Para ilustrar, o brasileiro Nelson Screnci é conhecido pelas suas pinturas paisagísticas e com raras exceções para outros gêneros; o estadunidense Patrick Kluga, além de pintar objetos específicos, também possui uma grande gama de pinturas de paisagens na corrente do hiper-realismo; o gênero paisagem, como o forte dos seus meios de expressão artística, também tem destaque em Tai Hsuan-An, arquiteto e pintor sino-brasileiro radicado em Goiânia, que possui o Cerrado como uma das fonte de suas inspirações.

18 "cabe aos novos artistas uma beleza ideal que não seja mais somente a expressão orgulhosa da espécie, mas expressão do universo, na medida em que a se é humanizado pela iluminação" (APOLLINAIRE, 2017 [1913], n.p., tradução livre).

19 "O que é essa pintura de paisagem? É dito que a pintura de paisagem morreu uma morte natural. Certamente, não existem mais grandes paisagens modernas comparadas com as do passado. Mas o que dessas não é comparável? Quais não são nem mesmo paisagens? É esse o ponto: o gênero mudou para além do reconhecível. Quando o cubismo quebrou a pintura ele também despedaçou a paisagem. Dificilmente a aparência específica de uma determinada paisagem será novamente o objetivo de um pintor importante. Contudo, ela pode ser seu ponto inicial. Pintura de paisagem deve ser agora subsumida sob a Pintura. Isso é todo que essa morte natural quer dizer." (BERGER, 2003, n.p., tradução livre).

\begin{tabular}{|c|c|}
\hline Caminhos de Geografia & Uberlândia-MG \\
\hline
\end{tabular}


Esses três artistas contemporâneos exemplificam grupos que, assim como os do passado, transitam por vários estilos de arte. É evidente que o gênero da paisagem não está na morte lenta anunciada por Berger (2003), mas se constata que mudou de perspectiva. No sentido em que as pinturas da contemporaneidade não são, nem intentam ser, como as pinturas do passado, a classificação do gênero paisagem não pode ser "fechado". Tal claustrofobia do classificado como paisagem no período anterior às vanguardas europeias fecha amplas possibilidades tanto para a Arte quanto para o conhecimento geográfico.

$\mathrm{Na}$ arte contemporânea outros modos de expressão artística tomaram uma posição de predominância, como as instalações e performances (ARCHER, 2012). Por essa ótica, a paisagem não é mais transposta em uma tela, mas a arte é inserida na paisagem e faz parte dela, como no caso da land art, corrente artística que utiliza a paisagem como centro e faz dela sua própria tela. Nessa perspectiva, Salgueiro (2001, p. 39) assim pontua:

Recentemente têm-se multiplicado as referências à "morte da paisagem". Esta morte refere-se tanto à evolução da pintura como à amplitude das transformações territoriais e à inexistência de modelos que as permitam apreciar. Efectivamente, a pintura de Cézanne e depois o cubismo acabaram com as regras de ouro da composição dita legítima, assente na perspectiva linear (visão a partir de um só ponto) e no escalonamento de planos, oferecendo-nos Kandinsky por 1912 uma Paisagem totalmente abstracta.

Percebe-se que a mudança no modo de se interpretar o gênero da paisagem foi uma provocação à própria forma de como era realizada a arte. No entanto, a ruptura não foi com o gênero em si, mas com como ele era representado. E, dessa forma, construiu novos arcabouços para paisagens de diferentes perspectivas, seja ela abstrata ou uma arte que está na paisagem.

Todavia, como, na perspectiva geográfica, pode-se debater o conceito da paisagem por meio das pinturas cubistas? Alguns indícios foram apontados na primeira parte do texto, mas o tema carece de mais debates. A pintura Paysage avec un arbre (1914), de Gleizes, por exemplo, colabora para tal aprofundamento.

Paysage avec un arbre (Figura 03) é uma obra que possui diversos significados e significantes. Suas cores fortes, de pinceladas parecidas com as realizadas em Landscape (Figura 01), e suas formas levam o olhar imediatamente para o centro da pintura. A árvore, elemento que se entende como pertencente uma paisagem dita natural, aqui é separada da própria paisagem.

A árvore não se situa no centro da tela. Contudo, ela alude aparições em poucas partes da obra, ao mesmo passo em que ela pode estar em toda a tela, "esparramada" entre colorações diferentes. O central é a paisagem que muitas vezes configuramos como construída: as casas, ponte, e outros elementos "humanizados" na paisagem. Sendo assim, a composição da pintura é uma provocação: o que é, nela, a paisagem? Há separação entre seus elementos? Clément (1994, p. 229) assim aborda a questão:

\footnotetext{
Palimpseste, mosaïque ou combinaison, sont différentes façons de désigner le paysage. La notion de paysage se situe donc bien au coeur de notre problématique homme-milieu. C'est un objet géographique riche, polysémique, offrant des angles d'approche multiples. Essayer de lui trouver un substitut serait une erreur. Le risque est de construire un concept en décalage par rapport à la problématique énoncée. La notion de paysage est celle qui s'impose. Son utilisation comme outil de recherche implique cependant un effort de rigueur dans la définition retenue. ${ }^{20}$
}

\begin{abstract}
20 "Palimpsesto, mosaico ou combinação, são diferentes maneiras de designar a paisagem. A noção de paisagem se situa, logo, no coração da nossa problemática homem-meio. Ela é um objeto geográfico rico, polissêmico, em que há múltiplos ângulos de abordagem. Ensaiar de buscar um substituto a ela seria um erro. $O$ risco é o de construir um conceito que esteja desconectado com a problemática enunciada. A noção de paisagem é aquela que se impõe. Sua utilização como ferramenta de pesquisa implica, portanto, em um esforço de rigor que a retêm em sua definição" (CLÉMENT, 1994, p.229, tradução livre).

$\begin{array}{lllll}\text { Caminhos de Geografia } \quad \text { Uberlândia-MG } & \text { v. 21, n. } 74 & \text { Abr/2020 } & \text { p. 87-107 } & \text { Página } 98\end{array}$
\end{abstract}


Figura 03 - Albert Gleizes, Paysage avec un arbre (1914). Óleo sobre tela, 100 x $81 \mathrm{~cm}$. Coleção privada.

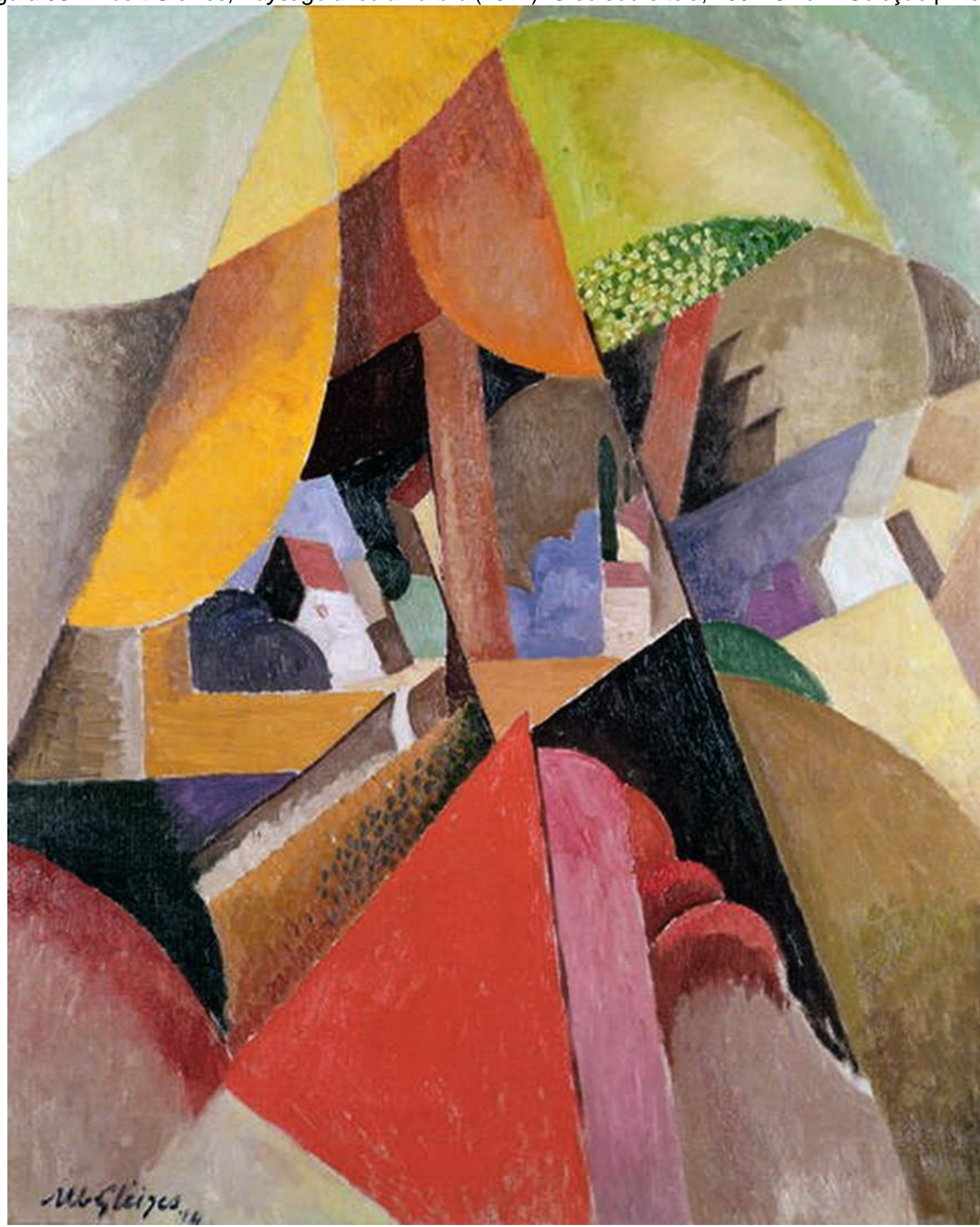

As múltiplas definições, ao mesmo tempo em que são diferentes, têm suas similitudes. A discussão de paisagem geralmente parte da relação entre sujeito e meio, sendo separados, ou um em sobreposição ao outro. O principal paradigma é esse. Como entendermos a paisagem por meio das práticas dos sujeitos e suas relações que são construtivas e não destrutivas ou separadas do meio?

Besse (2006, p. 64) explana que "a paisagem é um signo, ou um conjunto de signos, que se trata então de aprender a decifrar, a decriptar, num esforço de interpretação que é um esforço de conhecimento, e que vai, portanto, além da fruição e da emoção. A ideia é então que há de se ler a paisagem". A leitura da paisagem acompanha a perspectiva de se entender determinada espacialidade, seus elementos e sua própria concepção.

Ler uma paisagem exige, antes, uma preconcepção dela. A composição da paisagem em Paysage avec un arbre (1914) evidencia suas várias perspectivas sem um lugar exato de onde foi feita. Mesmo sem

$\begin{array}{lllll}\text { Caminhos de Geografia } \quad \text { Uberlândia-MG } & \text { v. 21, n. } 74 \quad \text { Abr/2020 } & \text { p. 87-107 } & \text { Página } 99\end{array}$


saber o lugar exato de onde foi concebida, por meio dela é possível lembrar e imaginar uma paisagem compósita que já vivenciamos.

Para Dardel (2011, p. 31),“a paisagem não é um círculo fechado, mas um desdobramento. Ela não é verdadeiramente geográfica a não ser pelo fundo, real ou imaginário, que o espaço abre além do olhar". Pensar a paisagem como totalidade ou como fixidez implica tomar o tempo e o espaço como estáticos. Nesse sentido é importante compreender a abertura, sua amplidão expansiva, como maneira de expandir sua geograficidade.

Paysage avec un arbre provoca a imaginarmos, pensarmos e vermos para além do nosso olhar. Essa pintura evidencia que a paisagem é dinâmica, transcendente a uma determinação temporal e espacial. É o que as pinturas cubistas provocam ao olhar do espectador. Há várias interpretações para cada pintura, elas dependem da subjetividade de quem a vê, elas superam a intenção originária do artista.

$\mathrm{Na}$ mesma linha de raciocínio, Relph (1976, p. 122-123) aborda que "landscapes always possess character that derives from the particular association of their physical and built characteristics with the meanings they have for those who are experiencing them". ${ }^{21}$ Ou seja, é por meio da experiência que podemos realmente compreender e sentir a paisagem.

Os significados serão múltiplos e a paisagem nunca será a mesma para duas pessoas diferentes, pois cada um é dotado de experiências, histórias, memórias e vivências singulares. Por conseguinte, a associação física da paisagem só é possível por intermédio dessas relações.

A própria pintura é um ambiente vívido que nos permite entrar em mundos diferentes pela via da imaginação que é composta por nossas experiências. Pela nossa perspectiva, Paysage et un arbre (Figura 03) revela-nos que a paisagem é um compósito no qual a construção social e a natureza são um todo conjunto e complexo. São diferentes, entretanto estabelecem uma relação que pode ser simbiótica.

A relação simbiótica advém da conexão do sujeito com a paisagem, pois ambos fazem parte de um mesmo organismo dinâmico. Por isso, a separação muitas vezes pode levar à destruição, já que o sujeito faz parte do meio e, por essa via, ele o vivencia diretamente e indiretamente. Berger (2003, não paginado) assim elabora: "When I am not here I might dream of this landscape. In my dream I would recognize it. I would recognize it, not in terms of previous events, but by its colour, the forms of its hills, its textures and its scale. I would recognize it before I could distinguish between a cherry and an apricot tree"22.

A paisagem, nesse caso, está mais ligada à natureza, a uma visão pictórica dela. Enquanto conceito é descrito como paisagem natural. Mas, ao vivenciarmos essa paisagem, nós mesmos não nos tornamos natureza? O sonho, ligado à imaginação e memória, se torna uma representação da realidade de quem vê tais elementos e os compõe em unicidade. No entanto, o corpo é o principal intermediário de tal relação e é por ele que se vivencia, posto que faz parte do sujeito.

A imaginação é um dos principais elementos para os cubistas (APOLLINAIRE, 2017 [1913]). Conforme já apontado, no movimento não são tratadas formas puras, mas diversas perspectivas imaginadas e aludidas de um determinado objeto, ou, no caso, da paisagem transposta para a tela. Metzinger e Gleizes (1964 [1912], p. 7) nos levam a pensar no conceito geográfico de paisagem ao se inquietarem:

Let us imagine a landscape. The width of the river, the thickness of the foliage, the height of the banks, the dimensions of each object and the relations of the dimensions - these are secure guarantees. Well, if we find these intact upon the canvas, we shall have learned nothing as to the talent or the genius of the painter. The worth of river, foliage, and banks, despite a conscientious faithfulness to scale, is no longer measured by width, thickness, and height, nor the relations between these dimensions. Torn from natural space, they have entered a different kind of space, which does not assimilate the proportion observed. This remains an external matter. It has just as much importance as

21 "paisagens sempre possuem um caráter que deriva da associação particular de suas características físicas e construídas conjuntamente aos significados delas para aqueles que as experienciam" (RELPH, 1976, p. 122-123, tradução livre).

22 "Quando eu não estou aqui eu posso sonhar dessa paisagem. No meu sonho eu a reconheceria. Eu a reconheceria não em termos de eventos prévios, mas por sua cor, a forma de seus morros, suas texturas e escalas. Eu a reconheceria antes que pudesse distinguir entre uma cerejeira ou uma árvore de pinha." (BERGER, 2003, n.p., tradução livre).

$\begin{array}{lllll}\text { Caminhos de Geografia } \quad \text { Uberlândia-MG } & \text { v. 21, n. } 74 \quad \text { Abr/2020 } & \text { p. 87-107 } & \text { Página } 100\end{array}$


a catalogue number, or a title at the bottom of a picture-frame. To contest this is to deny the space of painters; it is to deny painting. ${ }^{23}$

Ao transpor as imagens que são vistas pela perspectiva congelada e passá-las para a tela, o seu sentido deixa de existir. Não há como identificar exatamente as dimensões reais do que se percebe, mesmo respeitando-se, em certo ponto de vista, as características de cada componente presente na paisagem.

Ao se transpor para uma forma bidimensional, congelada, nada se apreende. Ao se transpor de uma forma diferente, sem exatamente ser medida, mas de uma forma em que se valoriza a percepção do pintor, a qualidade da pintura é mais bem mesurada. É possível compreender os aspectos das paisagens em perspectivas diferentes e colocá-los na tela dessa forma. Tal característica colabora com o talento da pintura, que não tem como papel representar o que é visto, mas mostrar o que é apreendido e, assim, ser contemplado.

Metzinger e Gleizes (1964 [1913]) provocam o convencional da pintura ao também questionarem o papel do pintor, da valorização, da qualidade das obras, no lugar da quantidade. Com tais argumentos, entendese que a pintura cubista objetiva quebrar as barreiras da planificação dos objetos, bem como retornar ao que pode ser contemplado, mas não repetido.

Nesse sentido, as pinturas cubistas conseguem capturar a paisagem em suas diferentes composições, de uma forma quadrimensional, com o intuito de não apenas representá-la, mas de apresentar a paisagem tal como eles, pintores, vivenciam-na e, assim, nos deixam vivenciar. Por conseguinte, ao consideramos os geógrafos citados anteriormente (Clemént, 1994; Besse, 2006; Dardel, 2011; Relph, 1976), suas leituras de paisagens nos apontam pistas para as pinturas cubistas, que possuem características únicas. Elas são investigadas por nós buscando ver e vivenciar a paisagem pela experiência e não apenas como uma imitação do que é formulado por real.

A representação da paisagem, nessa perspectiva, fica um tanto quanto comprometida, a se considerar a maneira como ela é apresentada. Situada de maneira corpórea e pela ação e práticas daquele que vê a paisagem, ela não representa uma unicidade de maneira comum ao grupo. Ela conforma um desdobramento subjetivo e que considera sua relação dimensional subjetivo-objetivo.

A paisagem, dessa maneira, é formulada pela tensão. Para Rose e Wylie (2006, p. 475),

[...] central to this is the tension of presence/absence, and of performing, creating, and perceiving presence. The nature of presence (as a horizon, a marking, a dwelling, a construction), and the issue of how presence and absence emerge and entwine (produced, embodied, perceived, affected), is the problem of landscape. ${ }^{24}$

A paisagem é formada pela tensão, pelas diferenças e similitudes entre as relações em que é problematizada.

Tal conceito, observado pela ótica das pinturas de Gleizes, mostra e intenta romper tal tensão. Todos esses elementos estão presentes em unicidade, de forma a corroborar entre si. Por isso a prática do sujeito é importante. Por meio dela é possível compreender a paisagem de maneira a transcender suas diferenças e alcançar entendimentos de suas sutilezas.

A paisagem, para além de uma definição do espaço material, é constituída pelas performances nela imanentes (ROSE, 2002). A relação da imaterialidade do espaço e da paisagem revelada pelos cubistas

23 "Deixemo-nos imaginar uma paisagem. A largura de um rio, a grossura da mata, o tamanho das margens, as dimensões de cada objeto e as relações dessas dimensões - essas são garantias seguras. Bem, se nós encontramos elas intactas na tela, nós não teremos aprendido nada sobre o talento ou genialidade do pintor. O valor do rio, da mata, das margens, ainda que com respeito consciente à escala, não é mais medido pela largura, grossura e tamanho, nem pelas relações entre essas dimensões. Arrancadas do espaço natural, elas entraram um tipo diferente tipo de espaço, o que não assimila a proporção observada. Isso mantem-se como matéria externa. Ela tem tanta importância quanto o número de um catálogo ou o título na beirada de uma moldura. Contestar isso é negar o espaço dos pintores, é negar a pintura." (METZINGER; GLEIZES, 1964, p.7, tradução livre).

24 "Central para isso é a tensão presença/ausência e a de performar, criar e perceber presença. A natureza da presença (como horizonte, marca, habitar, construção), e a questão de como a presença e ausência emergem e se entrelaça (produzida, incorporada, percebida, afetada) é o problema da paisagem." (ROSE E WYLIE, 2006, p. 475). 
deriva do fato que "ces peintres, s'ils observent encore la nature, ne l'imitent plus et ils évitent avec soin la représentation de scènes naturelles observées et reconstituées par l'étude" 25 (APOLLINAIRE, 2017, não paginado).

Diferentemente de Paysage et un arbre, em Head in a Landscape (Figura 04), Gleizes situa o sujeito como o núcleo fundante da paisagem. Dominantemente, em meio a cores mais escuras e pinceladas bruscas, como nas outras telas do início de sua carreira, a face parece controlar a profundidade daquilo que se encontra atrás dela. As casas, árvores, e outros elementos aparecem convergindo para a cabeça humana.

Tal pintura revela a visão de Gleizes da dominação do humano em relação à natureza e nas construções que ele faz. Ao mesmo passo, considerando seus escritos e pinturas, pode ser uma crítica ao modo de dominação que ocorre por parte do humano, ou a significação de que a cabeça pertença à paisagem, e não o contrário. Essa ambiguidade é um núcleo problematizador que possibilita pensar a relação paisagem-sujeito.

Consideremos que "paysage et milieu physique ne sont ainsi pas à confondre, car le paysage n'existe que par le groupe humain et l'homme, en particulier à travers la relation phénoménologique entre le je et le milieu"26 (BAILY; RAFFESTIN ; REYMOND, 1980, p. 278). Por "milieu physique" entendem-se a Geografia Física, o Clima, Geologia, Hidrografia e outros estudos do meio físico. Aqui, a separação entre esse meio e a paisagem denota que a paisagem seria a forma pura, e o meio, aquele que o sujeito ocupa.

Figura 04 - Albert Gleizes, Head in a Landscape (1912-13). Óleo sobre tela, 37,6 x 50,4 cm. Acervo Museu Solomon R. Guggenheim, Nova York.

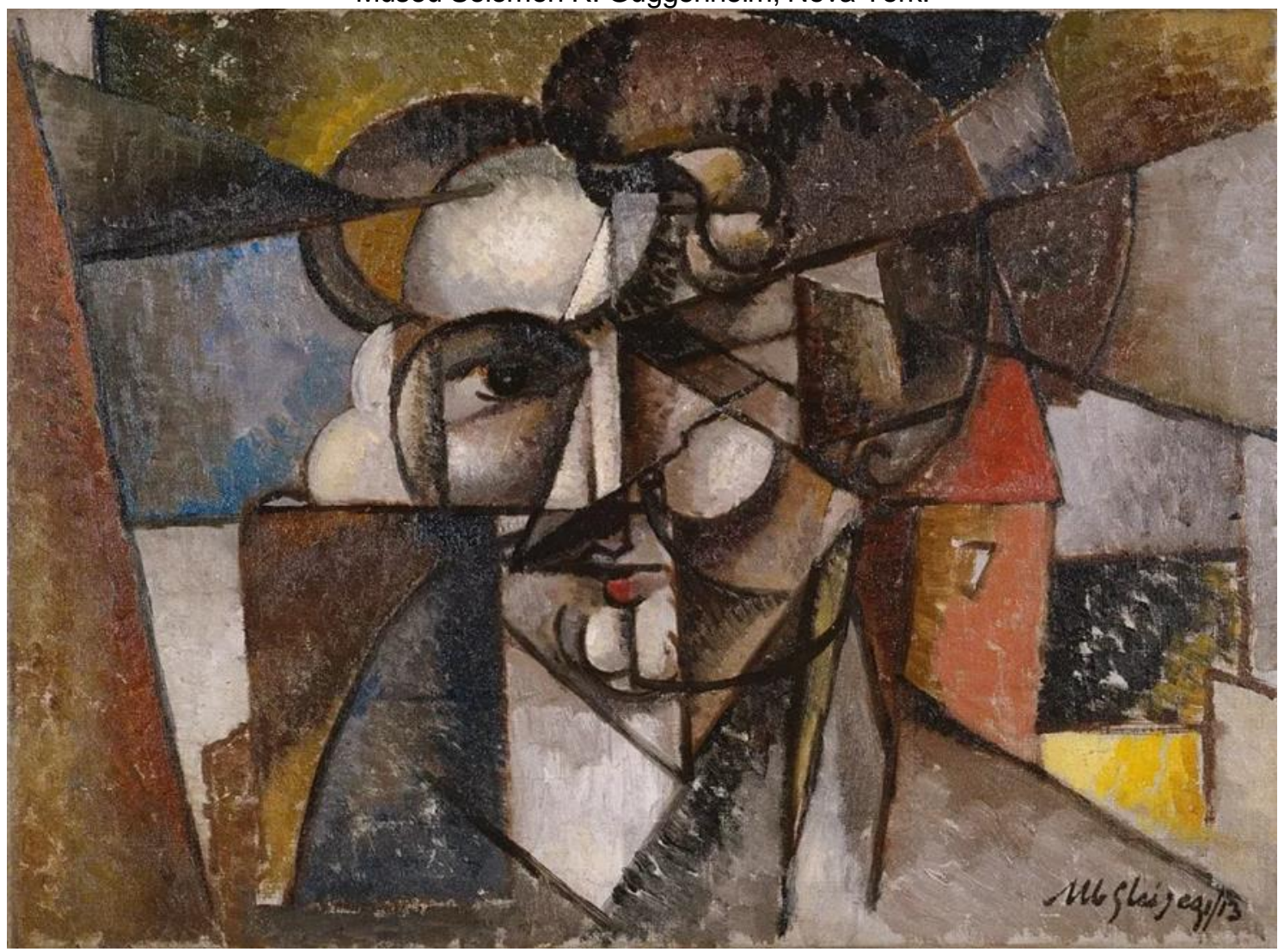

25 "Esses pintores, se observarem novamente a natureza, não a imitarão mais e evitarão com certeza a representação de cenas naturais observadas e reconstituídas pelo estudo." (APOLLINAIRE, 2017, n.p., tradução livre).

26 "paisagem e meio físico não são confundíveis, pois a paisagem não existe se não por um grupo humano e o homem, em particular por meio da relação fenomenológica entre o eu e o meio" (BAILY, RAFFESTIN, REYMOND, 1980, p. 278, tradução livre). 
No entanto, como a paisagem não existe sem o sujeito, mesmo sem sua presença (DARDEL, 2011), o meio é constituinte da paisagem em uma relação simbiótica. Essa separação, vale assinalar, é realizada principalmente quando se trata de representação da paisagem na pintura desconstruída pelos cubistas. Head in a Landscape (Figura 04) demonstra essa relação, seja de dominação ou não, o sujeito está lá, ele é tão separado da paisagem quanto a árvore de Paysage et un arbre (Figura 03).

Nesse sentido, pode-se completar com os escritos de Dardel (2011, p. 32), ao assinalar que "a paisagem não é, em sua essência, feita para se olhar, mas a inserção do homem no mundo, lugar de um combate pela vida, manifestação de seu ser com os outros, base de seu ser social". A paisagem, com esse entendimento, também reflete o ser social do sujeito e ajuda a aprofundar suas ideologias.

A paisagem é, assim, formada por ideologias e imaginários que são impressos de diferentes formas. Tal sinergia é fundamental para a manifestação de sua sociabilidade. No sentido de que "paysages et humanité sont liés dans un processus évolutif du à un modelage réciproque, et sans doute incontrôlable" 27 (FOREST, 2007, p. 101-102), há um processo continuo de reciprocidade por meio da qual paisagem e sujeito se (re)constituem em devir.

A obra de arte pode e revela tais condições. Por intermédio dela é possível nos encontrar pela e na paisagem. Metzinger e Gleizes (1964 [1912], p. 9) apontam que "the diversity of the relations of line to line must be indefinite; on this condition it incorporates quality, the unmeasurable sum of the affinities perceived between that which we discern and that which already existed within us; on this condition a work of art moves us"28. A obra cubista, ao intencionar e desvelar a simbiose espaço-sujeito como infinito, revela as relações que existem nos objetos, nas paisagens, ou outra perspectiva que o pintor desejar expressar.

Refere Cosgrove (1998, p.13), nessa direção:

[...] landscape denotes the external world mediated through subjective human experience in a way that neither region nor area immediately suggest. Landscape is not merely the world we see, it is a construction, a composition of that world. Landscape is a way of seeing the world. ${ }^{29}$

Por meio da paisagem os mundos são possíveis. O reflexo que vem advém da subjetividade e nós mesmos o construímos. O sujeito, portanto, vê o mundo pela sua experiência da/na paisagem. De maneira simbiótica, paisagem e sujeito não podem ser vistos de outra maneira que não como formas de um mesmo organismo. Ao mesmo passo, assinalam Metzinger e Gleizes (1964, p. 13):

There is nothing real outside ourselves, there is nothing real except the coincidence of a sensation and an individual mental direction. Far from us any thought of doubting the existence of the objects which strike our senses; but, being reasonable, we can only have certitude with regard to the images which they make blossom in our mind. ${ }^{30}$

O que vemos como realidade é aquilo que queremos que seja realidade. Mas o que afinal é real? Os sentidos, as conexões entres nós e os outros formam a realidade. Mesmo assim, é por meio de nosso imaginário que o mundo se forma. E por meio do corpo ele se conecta.

Graças às experiências podem-se identificar objetos, mas o real é apenas o que queremos que seja real. A realidade nada mais é do que uma relação entre a imaginação e a memória. E cada um de nós pertence a uma diferente e própria realidade.

27 "paisagens e humanidade estão inseridas em um processo evolutivo decorrente da modelagem reciproca e sem dúvida incontrolável” (FOREST, 2007, p.101-102, tradução livre)

28 "a diversidade das relações linha à linha deve ser indefinida; nessa condição ela incorpora qualidade, a não mensurável soma das afinidades percebidas por maio daquilo que podemos discernir e que já existiam em nós; nessa condição um trabalho de arte mobiliza-nos" (METZINGER; GLEIZES, 1964 [1912], p.9, tradução livre).

29 "Paisagem denota o mundo externo mediado pela experiência humana subjetiva de um modo que nem região ou área imediatamente sugerem. Paisagem não é meramente o mundo que vemos, é uma construção, uma composição desse mundo. Paisagem é um modo de ver o mundo" (COSGROVE, 1998, p.13, tradução livre).

30 "Não há nada real para além de nós, não há nada real exceto a coincidência de uma sensação e uma direção mental individual. Longe de nós qualquer pensamento de dúvida da existência dos objetos que atingem os nossos sentidos; mas, sendo razoáveis, nós podemos apenas ter certeza no que concerne as imagens que eles fazem florescer nas nossas mentes." (METZINGER; GLEIZES, 1964, p. 13, tradução livre).

$\begin{array}{lllll}\text { Caminhos de Geografia } & \text { Uberlândia-MG } & \text { v. 21, n. } 74 & \text { Abr/2020 } & \text { p. 87-107 Página } 103\end{array}$


Além disso, não apenas de imagens a realidade pode surgir, visto que os outros sentidos enervam e constituem a paisagem. Logo, é a partir do encontro, da comunicação sensorial com o mundo, que se constituem paisagens, efetivando, desse modo, ideologias, reformulações e construções.

Sendo assim, as pinturas não revelam a realidade em si, já que a realidade está no que cada um pensa do que vê, ouve, cheira, toca. Mediante essas percepções corporais, não apenas da visão, a realidade é modificada e criada com base naquilo que se tem como referência. Essa é a impossibilidade de se representar com exatidão o que se vê. Portanto, conforme Dewsbury $(2014$, p. 8):

Landscape can change the body encountering it, which is to say that the body never leaves the field of a landscape the same as it enters it. This is precisely where a nonrepresentational account of landscape pushes at the limits of the representational in seizing upon this ongoing cusp of a human's becoming. ${ }^{31}$

A corporeidade é dimensionada por intermédio do nexo sensível pela qual a paisagem emerge da menteconsciência. Ela não está em nossa mente e por ela se constitui. Uma árvore não é uma árvore se assim não for denominada. Assim como uma paisagem não é uma paisagem se assim não for considerada. Contudo, os limites da representação fazem com que seu rompimento seja necessário para compreendermos a paisagem em sentidos corpóreos de forma simbiótica.

O encontro entre mundos, corpos, faz com que modifiquemos nossa própria maneira de ver. Isso também se transforma em realidade. Na não representação, o corpo é o principal meio de comunicação e é por ele que se percebe, ao mesmo passo que é por ele que se transforma a realidade interior em realidade exterior. Por certo, a não representação puxa os limites da representação ao apontar outros elementos, aqueles relacionados às práticas cotidianas de relação e comunicação com o mundo.

A arte, com os cubistas, principalmente ao deixar as amarras de lado, pôde mostrar que o mundo não precisa ser de apenas um ponto de vista. Não há totalidade e nem fragmentação, há sensibilidade e percepção. Como provoca o ensaio dos artistas:

Let the picture imitate nothing and let it present nakedly its raison d'être! Then we should indeed be ungrateful were we to deplore the absence of all those things - flowers, or landscape, or faces - whose mere reflection it might have been. Nevertheless, let us admit that the reminiscence of natural forms cannot be absolutely banished; as yet, at all events. An art cannot be raised all at once to the level of a pure effusion. (METZINGER; GLEIZES, 1964, p. 7). ${ }^{32}$

A paisagem pode ser considerada e investigada como uma relação corpórea do sujeito com o mundo, buscando constituir suas próprias impressões. No entanto, a paisagem percebida é "recebida"? Há dialogia entre o sujeito e a paisagem? Ou, sem ser via arte, somos todos produtos de uma paisagemmercadoria?

Tais indagações são provocações para pensarmos a paisagem sem separações, ainda que sem a totalizar de um modo "fechado". É preciso vê-la de diferentes perspectivas, urbana, rural, cultural, vernacular e outras, que só são constituídas pelo sujeito. Uma perspectiva aberta de paisagem implica uma noção de um todo complexo que possa ser interpelado por diferentes dinâmicas e experiências.

Destarte, em estilo Cubista, depois de debatemos a paisagem pelas suas obras, Gleizes foi o artista selecionado como fio condutor, seguindo o apontamento de Apollinaire (2017, não paginado, [1913]):

31 "Paisagem pode mudar o corpo que a encontra, o que significa que o corpo nunca abandona o campo da paisagem no mesmo momento que adentra nela. Isso é precisamente onde uma abordagem nãorepresentacional da paisagem vai na direção dos limites do representacional em apropriar-se dessa "beira" dinâmica do devir humano." (DEWSBURY, 2014, p.8, tradução livre).

32 "Deixe que a imagem nada imite e permita que ela apresente nu sua raison d'être! Só então poderemos realmente ser ingratos se deploramos a ausência de todas essas coisas - flores, paisagem ou faces - cujo mero reflexo deveria ter sido pintado. Todavia, deixe-nos admitir que a reminiscência das formas naturais não pode ser absolutamente banida; por agora, de toda forma. Uma arte não pode ser erguida instantaneamente ao nível de efusão pura." (METZINGER; GLEIZES, 1964, p. 7, tradução livre).

$\begin{array}{lllll}\text { Caminhos de Geografia } \quad \text { Uberlândia-MG } & \text { v. 21, n. } 74 \quad \text { Abr/2020 } & \text { p. 87-107 } & \text { Página } 104\end{array}$


Toutes les figures des tableaux d'Albert Gleizes, ne sont pas la même figure, tous les arbres, un arbre, tous les fleuves, un fleuve, mais le spectateur, s'il peut s'élever jusqu'aux idées générales pourra fort bien généraliser cette figure, cet arbre ou ce fleuve parce que le travail du peintre a fait monter ces objets à un degré supérieur de plasticité, a un degré de plasticité tel, que tous les éléments qui en constituent les caractères individuels sont représentés avec la même majesté dramatique. ${ }^{33}$

Como um dos principais pintores do movimento Cubista, Gleizes, além de contribuir para compreendermos o movimento com Cubismo em companhia de Metzinger, foi um grande contribuidor para as pinturas de paisagens cubistas. No entanto, assim como vários outros artistas do circuito, não é um dos mais conhecidos, assim como seu próprio ensaio. Sendo Apollinaire um grande escritor e intelectual respeitado na época, seu ensaio acerca dos cubistas foi mais bem aceito do que a obra dos próprios artistas.

No entanto, Apollinaire aponta Gleizes como um dos principais teóricos do movimento. Mesmo que Picasso e Braque tenham sido os precursores do cubismo, eles não faziam parte do circuito artístico efetivo e preferiam trabalhar separadamente (APOLINAIRE, 2017 [1913]). Por conseguinte, na história da Arte, assim como em vários outros movimentos, alguns artistas ficaram um pouco mais invisibilizados.

Gleizes, no entanto, merece ser reconhecido pelas suas contribuições no estudo profundo do cubismo, em formas, cores, luz, e sua forma nada ortodoxa de trabalho. No campo do gênero da paisagem, ele é uma grande fonte para nós, praticantes da Geografia, no estudo das (não)representações da paisagem.

\section{...E AINDA SEREMOS...}

A paisagem, muito discutida na geografia, desvela muitos questionamentos e problemáticas que podem ser explorados pelos geógrafos. Ao se relacionar com movimentos na Arte, o Cubismo, movimento de vanguarda no início do século XX, é um desses indícios de possibilidades de exploração. Utilizar a arte com o objetivo de compreender a paisagem como fenômeno corrobora na aproximação da ciência com a corporeidade do ser transpassada pelos movimentos artísticos.

Ainda que haja vários debates acerca da representação no Cubismo, principalmente no que se refere à paisagem, pode-se compreender que o próprio conceito de representação requer cuidados e aprofundamentos no que diz respeito às suas rupturas e utilizações. Logo, considerando que representação na arte é próxima da representação que utilizamos na Geografia, a representação instigada pelos artistas cubistas, dentre eles Albert Gleizes, revela outros modos de representar que culminam nas (não)representações e representações como a de Mondrian, por exemplo.

Outrossim, tais discussões realizadas neste texto sinalizam para futuras pesquisas e intensificação do estudo da paisagem para além do bidimensional e até mesmo do sensorial. A imaginação, que é presente no Cubismo, nos releva paisagens oníricas que são apresentadas pelo também movimento de vanguarda, o Surrealismo.

O diferente, o novo, aos olhos de muitos, contribui para profundas reflexões e movimenta a ciência, e, no caso, o conceito de paisagem. Certamente, a Geografia Cultural, em suas diferentes abordagens, e seu diálogo com a arte contribuem para que essa oxigenação na Geografia ocorra por diferentes pontos de vista, sem necessariamente precisar anular o discordante.

Além disso, o debate da não representação, que tem surgido sobretudo no Reino Unido, pode ser um ponto de partida enriquecedor para os novos estudos do conceito de paisagem, como um jeito de pensar o sujeito e o mundo de forma corpórea, com interdisplinaridade. A teoria não representacional nos mostra um terreno amplo para pesquisas futuras que visam entender as vivencias nas/das paisagens contemporâneas.

33 "Todas as figuras das telas de Albert Gleizes não são a mesma figura, todas as árvores, uma árvore, todas os córregos, um córrego, mas o espectador, se ele puder se elevar até as ideias gerais poderá claramente generalizar cada figura, essa árvore ou aquele córrego, pois o trabalho do pintor fez com que esses objetos fossem mostrados em um grau maior de plasticidade, um grau de plasticidade em que todos os elementos que constituem os caracteres individuais são representados com a mesma grandeza dramática." (APOLLINAIRE, 2017 [1913], n.p., tradução livre).

$\begin{array}{lllll}\text { Caminhos de Geografia } \quad \text { Uberlândia-MG } & \text { v. 21, n. } 74 \quad \text { Abr/2020 } & \text { p. 87-107 } & \text { Página } 105\end{array}$




\section{REFERÊNCIAS}

ALMEIDA, M. G. Em busca do poético do sertão: um estudo de representações. In: ALMEIDA, M. G.; RATTS, A. J. P. Geografia: leituras culturais. Goiânia: Alternativa, 2003. p. 71-88.

ALMEIDA, M. G. A propósito do trato do invisível, do intangível e do discurso na Geografia Cultural. Anpege, Fortaleza, v. 9, n. 11, p. 41-50, jan.-jun. 2013. https://doi.org/10.5418/RA2013.0911.0004

AMBROSIO, C. Cubism and the fourth dimension. Interdisciplinary Science Reviews, v. 41, n. 2-3, p. 202221, 2016. https://doi.org/10.1080/03080188.2016.1223586

APOLLINAIRE, G. Les peintres cubistes: méditations esthétiques [1913]. Montreal: Project Gutenberg, 2017. [E-Book].

ARCHER, M. Arte contemporânea. São Paulo: Martins Fontes, 2012.

ARGAN, G. C. Arte moderna: do lluminismo aos movimentos contemporâneos. São Paulo: Companhia das Letras, 1992.

BACHELARD, G. A poética do espaço. 2. ed. Trad. Antonio de Pádua Danesi. São Paulo: Martins Fontes, 2008.

BAILLY, M. A. S.; RAFFESTIN, C.; REYMOND, H. Les concepts du paysage: problématique e représentations. Espace Géographique, n. 9, p. 277-285, 1980. https://doi.org/10.3406/spgeo.1980.3575

BERGER, J. Painting a landscape. In: Select essays. New York: Random House, 2003. [E-Book].

BERQUE, $A$. Position de recherche: la transition paysagère ou sociétés à pays, à paysage, à shanshui, à paysagement. Esoace Géographique, v. 18, n. 1, p. 18-20, 1989. https://doi.org/10.3406/spgeo.1989.2820

BESSE, J. Ver a terra: seis ensaios sobre a paisagem e a geografia. São Paulo: Perspectiva, 2006.

CLAVAL, P. Uma, ou Algumas abordagem(ns) cultural(is) na Geografia Humana? In: SERPA, A. (Org.). Espaços culturais: vivências, imaginações e representações. Salvador: EDUFBA, 2008. p. 13-29.

CLÉMENT, M. V. Contribution épistémologique à l'étude du paysage. Mélanges de la Casa de Velázquez, t. 30-33, p. 221-237, 1994. https://doi.org/10.3406/casa.1994.2718

COSGROVE, D. Social formation and symbolic landscape. Madison: The University of Wisconsin Press, 1998 [1984].

DARDEL, E. O homem e a terra. Trad. Werther Holzer. São Paulo: Perspectiva, 2011.

DEWSBURY, J. Non-representational landscapes and the performative affective force of habit: from "Live" to "Blank", Cultural Geographies, p. 1-19, 2014. https://doi.org/10.1177/1474474014561575

FERRAZ, C. B. O. Geografia: o olhar e a imagem pictórica. Pro-posições, v. 20, n.3, p. 29-41, 2009. https://doi.org/10.1590/S0103-73072009000300003

FOREST, J. P. Sur l'introduction expérimentale du premier signe humain dans les paysages naturels. Ateliê Geográfico, v. 1, n. 1, p. 94-105, 2007. https://doi.org/10.5216/ag.v1i1.2719

GIL FILHO, S. F. Geografia Cultural: estrutura e primado das representações. Espaço e Cultura, Rio de Janeiro: UERJ, n. 19-20, p. 51-59, 2005.

GOMBRICH, E. H. A história da arte. Rio de Janeiro: Livros Técnicos e Científicos, 2013.

GOMPERTZ, W. What are you look at? The Surprising, Shocking and Sometimes Strange Story of 150 Years of Modern Art. New York; Peguin Group, 2012.

HAWKINS, H. Creative geographic methods: knowing, representing, intervening: on composing place and page. Cultural Geographies, v. 22, n. 2, p. 247-268, 2015. https://doi.org/10.1177/1474474015569995

HUGHES, R. The Shock of the new. New York: Peguin 1991. (E-Book).

MERLEAU-PONTY, M. A dúvida de Cézanne. In: MERLEAU-PONTY, M. O olho e o espírito. São Paulo: Cosac Naify, 2013. p. 123-149.

METZINGER, A.; GLEIZES, J. Cubism. [1912] In: HERBERT, R. L. Modern artists on art: ten unabridged essays. New Jersey: Englewood Clifs, 1964. p. 1-18. 
RELPH, E. Place and placelessness. London: Pion Limited, 1976.

ROSE, M. Landscape and labyrinths. Geoforum, v. 33, p. 455-467, 2002. https://doi.org/10.1016/S00167185(02)00030-1

ROSE, M. Landscape. The international Encyclopedia of Geography, p. 1-10, 2017. https://doi.org/10.1002/9781118786352.wbieg0794

ROSE, M.; WYLIE, J. Animating landscape. Environment and Planning D: Society and Space, v. 24, p. 475-479, 2006. https://doi.org/10.1068/d2404ed

SALGUEIRO, T. B. Paisagem e Geografia. Finisterra, v. 32, n. 72, p. 37-53, 2001.

SERPA, Â. Paisagem, lugar e região: perspectivas teórico-metodológicas para uma Geografia humana dos espaços vividos. GEOUSP - espaço e tempo, São Paulo, n. 33, p. 168-185, 2013. https://doi.org/10.11606/issn.2179-0892.geousp.2013.74309

SÖDERSTRÖM, O. Representation. In: SIBLEY, D.; JACKSON, P.; ATKINSON, D.; WAHSBOURNE, N. Cultural Geography: a critical dictionary of key concepts. New York: Palgrave Macmillan, 2005. p. 11-15.

Recebido em: 20/06/2019

Aceito para publicação em: 20/03/2020 